also due to the lowering of blood viscosity. Charm et al reported that plasma viscosity in joggers is lower than that in those who do not jog. ${ }^{6}$ The Munich group headed by Ernst has published several studies showing that exercise increased red cell deformability and reduced blood viscosity. ${ }^{78}$ Several studies also show that many factors, including cholesterol and noradrenaline, reduce red cell deformability.

Exercise lowers plasma cholesterol and noradrenaline concentrations, ${ }^{2}$ and these changes seem to be shown by improved red cell deformability, which lowers blood viscosity. This concept provides a basis for understanding why both increased physical activity and appropriate dietary changes may lower blood pressure. Therefore those who by choice, or because of disability, do not exercise regularly can obtain haemorrheological benefits through diet alone that are similar to those induced by exercise.

University of Otago,

L O SIMPSON

Dunedin,

New Zealand

1 Morris JN, Heady JA, Raffle PAB, Roberts CG, Parks JW. Coronary heart disease and physical work. Lancet 1953;ii: 1053-7, 1111-20.

2 Nelson L, Jennings GL, Esler MD, Korner PI. Effect of changing levels of physical activity on blood pressure and haemodynamics in essential hypertension. Lancet 1986;ii: 473-6.

3 Harris I, McLoughlin J. The viscosity of the blood in high blood pressure. Quart f Med 1930;23:451-64.

4 Tibblin G, Bergentz S-E, Bjure J, Wilhelmsen L. Hemotocrit, plasma protein, plasma volume, and viscosity in early hyperensive disease. Am Heart 7 1966;72:165-76.

5 Letcher RL, Chien S, Pickering TG, Laragh JH. Elevated blood viscosity in patients with borderline essential hypertension. Hypertension 1983;5:757-62.

6 Charm SE, Paz H, Kurland GS. Reduced plasma viscosity among joggers compared with non-joggers. Biorheology 1979;16: $185-9$.

7 Ernst E, Schmid M, Matrai A. Intraindividual changes of haemorrheological and other variables by regular exercise. International fournal of Sports Cardiology 1985;2:50-4.

8 Ernst $\mathrm{E}$. Changes in blood rheology produced by exercise. J $A M A$ 1985;253:2962-3.

\section{Old and new causes of superficial dyspareunia}

SIR,-I was pleased to see Drs Alan J Riley and Peter Bromwich (29 August, p 513) emphasising the importance of a thorough examination of the vulva in cases of superficial dyspareunia and mentioning the recently recognised but poorly understood focal vulvitis. I am concerned, however, that while attention was given to the rare vulvitis circumscripta plasmacellularis, the much more common problem of lichen sclerosis et atrophicus was not mentioned. In this inflammatory, atrophic disorder the vulva has an ivory white appearance and lesions may become haemorrhagic. In time atrophy becomes pronounced, affecting the inner aspects of the labia majora, labia minora, clitoris, and vestibule, and the vaginal introitus often becomes constricted. The primary symptoms are itching and soreness, but dyspareunia results from the soreness and introital constriction.

Over seven years 345 patients (aged 20-75) were referred to a dermatology clinic with undiagnosed vulval problems by general practitioners, departments of genitourinary medicine, family planning clinics, and gynaecologists. Of these, $183(53 \%)$ had lichen sclerosis et atrophicus and $159(87 \%)$ of these experienced dyspareunia, graded as severe by more than half. The condition rapidly responds to the application of fluorinated steroid preparations, and all but two of my patients were completely cured of dyspareunia after three months treatment.

Other vulval dermatoses causing dyspareunia as a primary or associated symptom in this series were lichen simplex, intertrigo, contact dermatitis $(75 \%$ due to local anaesthetic preparations), infections, eczema, flexural psoriasis, lichen planus, and Crohn's disease. It is thus important to be aware of dermatological disorders of the vulva as a cause of dyspareunia. Biopsy may be necessary to confirm the diagnosis and should not be delayed as early treatment not only relieves symptoms and often much suffering but may prevent complications such as introital constriction, psychological problems, and malignant change.

\section{CHRISTINE I HARRINGTON}

Royal Hallamshire Hospital,

Sheffield S10 2JF

\section{The cost of nursing}

SIR,-I have every sympathy with Dr K W M Scott and colleagues in Wolverhampton (8 August, p 393) in their difficulties resulting from the imposed implementation of the English Nursing Board circular 86/65/ERDB. Indeed, everyone concerned with patient care must deplore the implications of the circular and its method of introduction-in particular the emphasis it places on theoretical instruction to the detriment of practical, in service training. Ms Lorraine $\mathrm{K} \mathrm{M}$ Brooks (29 August, p 555) may be dismayed at this attitude of medical staff-shared by many trained nurses-but Dr George Day's Personal View (22 August, p 498) unfortunately suggests that proper traditional nursing is what patients actually require. Ms Brooks seem to be more obsessed by the status of nurses than the welfare of patients; I would suggest that the one depends more on diligent attention to the other than increasing the period of classroom instruction by $70 \%$. The rather petulant comment that "Nurses have been handmaidens to the medical profession for too long, following orders without thought or knowledge" perhaps gives an insight into the true motive behind the proposed changes and hardly does justice to the intelligence of Ms Brooks's colleagues. Good nursing certainly requires knowledge-and much more besides-but as an essentially practical occupation it is best learnt principally in the ward rather than the classroom; the current course programme seems to strike a reasonable balance between the two.

Southampton General Hospital,

Southampton $\mathrm{SO} 9 \mathrm{XY}$

J M B BURN

\section{Visual analogue scores and urinary}

incontinence

SIR,-Dr M I Frazer and colleagues (5 September, p 582) correlate visual analogue scores with diagnoses of detrusor instability and genuine stress incontinence. They show a significant difference between the mean scores in the two groups but note that there was no clinically useful separation of the groups as the area of overlap was large. Furthermore, there was a large discrepancy between the results of this study and a previous study that used visual analogue scales.

Dr Frazer and coworkers comment that the psychological profiles of the two groups show clear differences. Recent work in this department, however, strongly suggests that this is not, in fact, the case. Personality testing using the Eysenck personality inventory has shown a high level of neuroticism in both groups of patients. ${ }^{1} \mathrm{~A}$ further study, recently completed, shows a high level of psychiatric morbidity $(47 \cdot 9 \%$ using the general health questionnaire), and no relation has been found between the urodynamic findings and the degree or type of psychiatric morbidity. It therefore seems that women with urinary incontinence of all types are equally likely to have psychiatric problems. Another interesting finding in our study was that urine loss, as measured by the "nappy" test, was unrelated to urodynamic or psychiatric results.

Our findings suggest that the relations among detrusor instability, anxiety, and demonstrable urine loss are not as straightforward as has previously been thought. This may help to explain the large overlap of results on visual analogue testing.

M MORRISON

L M MORRISON

A MCALISTER E S GLEN

Walton Urological Teaching and Research Centre,

Southern General Hospital,

Glasgow G51 4TF

1 Morrison LM, Eadie AS, McAlister A, Glen ES, Taylor J, Rowan D. Personality testing in 226 patients with urinary incontinence. Brf Urol 1986;58:387-9.

2 Morrison LM, Morrison M, Small D, McAlister A, Glen ES Psychiatric aspects of female incontinence. In: Proceedings of the International Continence Society 17 th annual meeting, Bristo 1987. London: International Continence Society, 1987: $139-40$.

\section{Arterial thrombosis associated with} graduated pressure antiembolic stockings

SIR,-Mr Dugal I Heath and colleagues (5 September, $p 580$ ) report two cases of arterial occlusion resulting from mishaps with graduated compression stockings. A thigh length stocking was responsible in their case 2 , and it seems likely that a thigh length stocking was, as commonly recommended by manufacturers, also fitted in case 1 .

We have recently completed a study of 110 patients undergoing major abdominal surgery who were randomly allocated to be fitted preoperatively with thigh length (54) or knee length (56) stockings, which were worn until discharge. There was no significant difference $(p<0.05)$ in the incidence of deep vein thrombosis detected by fibrinogen labelled with iodine-125 (thigh length three; knee length one). Knee length stockings were more acceptable to both patients and nursing staff.

We agree with the suggestions made by $\mathrm{Mr}$ Heath and colleagues but would suggest that arterial occlusion would have been avoided in their reported case 2 and might have been avoided in case 1 had knee length stockings, with their advantages of cost and acceptability, been substituted.

Mathew Porteous DAvid Negus

Lewisham Hospital

London SE13 6LH

\section{How to start in private practice}

SIR,-Mr Anthony E Young mars an otherwise lucid and humorous account of private practice (5 September, $p$ 593) with some naive comments that beg criticism

On the one hand, he reminds practitioners not to let their enthusiasm for private practice nibble into their National Health Service time, while, on the other, he seems to expect his National Health Service junior staff to help in the care of patients admitted to private beds in National Health Service hospitals. I would contend that junior staff do much more than resent time spent with these patients and that they know perfectly well that the so called educational value in the patient's con- 